\title{
Effects of acute shock on body weight are mediated by changes in food intake
}

\author{
S. L. RICKARDS, R. F. S. JOB, and R. A. BOAKES \\ University of Sydney, Sydney, New South Wales, Australia
}

\begin{abstract}
We examined the causal role of decreased food intake in the body weight pattern observed after exposure to intermittent footshock. In Experiment 1, relative to controls, shocked animals decreased food intake and lost weight in the 24-h test. An unshocked group whose food intake was yoked to the shocked group (food-yoked group) for the poststress period revealed that food intake was a sufficient cause of the body weight loss. In Experiment 2, after the first $24 \mathrm{~h}$, the shock group recovered food intake and body weight gain but did not compensate for the initial losses. Body weights of food-yoked animals again indicated that food intake was a sufficient cause of these effects. The lowered body weight of shocked animals at the end of testing was due to a transient hypoingestion and a failure to subsequently show a compensatory hyperingestion. Dess's (1991) regulatory shift hypothesis is refined in the light of these findings.
\end{abstract}

Stressors, such as electric shock, immobilization, noise, and crowding, that decrease body weight or body weight gain in rats are also capable of inducing anorexia (Alario, Gamallo, Beato, \& Trancho, 1987; Armario, Castellanos, \& Balasch, 1984; Chauoloff \& Zamfir, 1993; Donohoe, Kennett, \& Curzon, 1987; Kennett, Dickinson, \& Curzon, 1985a, 1985b; Ottenweller, Natelson, Pitman, \& Drastal, 1989; Wagner, Hall, \& Cote, 1977). In the helplessness literature there is ample evidence that foot- or tailshock decreases body weight (Brennan, Job, Watkins, \& Maier, 1992; Desan, Silbert, \& Maier, 1988; Dess, 1992; Dess \& Chapman, 1990; Dess \& Choe, 1994; Dess \& Minor, 1996; Dess, Minor, \& Brewer, 1989; Dess, Raizer, Chapman, \& Garcia, 1988; Kelsey, 1977, Experiment 3; Seligman, Maier, \& Solomon, 1971; Weiss, 1968, 1970) and food intake (Dess \& Vanderweele, 1994, Experiment 2; Weiss, 1968, 1970). However, the manner in which these changes may be related remains unclear.

The evidence from the few studies in which both body weight and ingestive changes have been examined appears to be contradictory. Weiss (1970, Experiment 3 ) and Dess et al. (1989) reported that shocked subjects recovered from a transient decrease in food intake in the 24 -h period including stress, to the levels of nonshocked controls. However, they reported different body weight outcomes. Weiss (1970) found that this recovery of ingestion supported a rate of weight gain similar to that of controls, but Dess et al. (1989) found that shocked subjects continued to lose weight relative to controls. A resolution of the discrepancy has supported the suggestion by Dess and colleagues (Dess et al., 1989) that differences in feeding

This research was supported by Australian Research Council Grant A79601341 to R. F. S. Job. Correspondence should be addressed to S. L. Rickards, Department of Psychology, University of Sydney, Sydney, NSW 2006, Australia (e-mail: sandrar@psych.su.oz.au). schedule between the two studies were critical. In a specific test of this hypothesis, which contrasted ad-lib food and feeding schedule conditions, the pattern of food intake and body weight was similar to that found by Weiss (1970) for subjects on ad-lib access to food and water (Rickards \& Job, 1997; Rickards, Job, \& Boakes, 1995). The dissociation of the two measures was also similar to that found by Dess and colleagues for subjects on the restricted feeding schedule.

In terms of Minor, Dess, and Overmier's (1991) modulator hypothesis, feeding schedule appears to be an extrinsic modulator of the basic effects of helplessness stress on the ingestion and body weight. It may be asserted, therefore, that general claims about the effects of stress on ingestion and body weight may not be derived from a design employing food restriction. The stress of food deprivation must obscure that of shock exposure.

The way in which food intake and body weight changes are related after exposure to a single session of stress remains unclear, even when attention is confined to designs employing ad-lib access to food and water. Given the results of Weiss $(1968,1970)$, Wagner et al. (1977), and Rickards et al. (1995) it seems that the relevant literature is consistent with, but does not provide unambiguous support for, the proposal that stress-induced changes in food intake at least partially account for the body weight pattern. One aim of the present paper, then, was to examine the possible role of stress-induced changes in food intake in body weight decreases by using a yoked-food design. An unshocked group (Y) were food-yoked to the shock group. That is, on the test day, subjects in this group had their maximum possible daily food intake determined by the intake of age- and weight-matched partners in the shock group. In Experiment 1, it was expected that if the decrease in food intake induced by stress is causal with respect to the body weight pattern, the shock and yokedfood groups would show the same weight outcome. 


\section{EXPERIMENT 1}

Experiment 1 allowed the identification of stressinduced changes in daily ad-lib food and water intake and body weight. This was achieved by comparing a group that received footshock (S) with a control group (C) that was placed in the shock apparatus for the equivalent amount of time without receiving shock. The hypothesis that the initial stress-induced reduction in feeding causes the body weight decrease was examined using the yokedfood design.

\section{Method}

Subjects. Thirty-six subjects were selected from an initial pool of 50 experimentally naive male Wistar rats obtained from the Little Bay Breeding Station. Selection was made on the basis of close matching for body weight and food intake. The subjects were between 109 and 116 days of age and weighed between 447 and $507 \mathrm{~g}$ at the start of the experiment. They were individually housed in plastic boxes with metal grille lids in a room with a constant temperature of $23^{\circ} \mathrm{C}$ and a $12: 12$-h light:dark cycle. The subjects were maintained in these conditions with ad-lib food and water for at least 1 week before the experiment began. All experimental manipulations occurred during the light period.

Apparatus. The shock session took place in identical clear Plexiglas boxes $20 \times 20 \times 24 \mathrm{~cm}$ high with a metal ceiling panel that could be lifted for access. The grid floor consisted of stainless steel bars $0.6 \mathrm{~cm}$ in diameter positioned $1.7 \mathrm{~cm}$ apart from center to center. Shock was delivered to the bars of the grid floor of the box using Hales shock generators and scramblers. The shock generators were calibrated, via a variable resistor, to supply alternating current at a peak to peak value of $1.0 \mathrm{~mA}$ scrambled rapidly. Each apparatus was positioned in a black sound attenuation chamber $64 \times 62 \times$ $64 \mathrm{~cm}$ high. There was no illumination, except for the minimal light allowed through the fan. The fan, housed in the rear wall, maintained air circulation and provided a background noise level of $64 \mathrm{~dB}$ (unweighted).

Procedure. The procedures in order were: baseline training, baseline measures, and group allocation, shock treatment, and poststress measures. Baseline training on Days 1-4 inclusive allowed adjustment, if any, to the food and water schedule, without affecting baseline measures. On a daily basis food and water were removed for measurement at 0800 , body weight measures were taken at 0830 , and food and water were returned at 1300 . This schedule equates access to food and water across days, including the day of treatment. This allows for comparison of intakes pre- and poststress. It necessarily involves a minimal amount of food and water restriction during the early light period. Such restriction early in the light portion of the 24-h cycle, however, has produced no effects that distinguish subjects from the relevant control group's body weight or feeding in the 24-h period that follows restoration of adlib food access (Bare \& Cicala, 1960; Larue-Achagiotis \& LeMagnen, 1983; LeMagnen, 1983). In terms of the impact on body weight, the schedule amounts to ad-lib access.

Food intake and body weight on Days 5 and 6 were used as baseline measures. These baseline measures were used in the allocation of subjects to groups and in the calculation of dependent variables. An initial match on weight within $10 \mathrm{~g}$, and on food intake within $5 \mathrm{~g}$, yielded 12 triads. Control and shock animals from the first and second triads were treated on Day 6 . Yoked animals from these triads were then treated on Day 7 to allow for the food-yoking procedure. Baseline measures were continued for all unallocated rats during this phase. Any adjustments to group allocations could therefore be made daily. This procedure was continued until all triads had been run.
The shock group received 110 footshocks of decreasing duration (average, $15.65 \mathrm{sec}$; range, $3-38 \mathrm{sec}$ ) with a random-duration intertrial interval (average, $90 \mathrm{sec}$; range, $30-150 \mathrm{sec}$ ). These shock parameters have produced helplessness-like debilitations in this laboratory (Balleine \& Job, 1991; Prabhakar \& Job, 1996). The control and yoked groups were exposed to the apparatus for a complete session but received no shocks. Food, water, and body weight measurements were made on the following day at the usual time. Foodyoking poststress was such that within each triad the food intake of the shock group rat poststress determined the food made available to the yoked rat for the same period.

Statistics. The Type I error rate of .05 was used for all analyses. All of the statistical tests reported here were planned contrasts with one-way analysis of variance. Planned contrasts compared Groups $\mathrm{C}$ and $\mathrm{S}$ and Groups $\mathrm{S}$ and $\mathrm{Y}$ for food and water intake and for body weight.

\section{Results}

Baselines. The three groups did not differ on any prestress measure ( $p$ s $>.1)$. Baseline means and standard errors are reported in Table 1 .

Food intake. Food intake is shown in Figure 1A, expressed as the change from baseline intake. Exposure to shock induced a decrease in feeding. Shocked subjects ate significantly less than controls $[F(1,33)=24.25, p<$ $.0001]$. The food-yoking procedure was successful, in that the food intake of the shocked and yoked groups did not differ $(p>.1)$. This indicated that the yoked subjects did not leave significant amounts of food.

Water intake. Water intake is shown in Figure 1B, expressed as the change from baseline. There were no group differences in water intake. Although the intake of yoked subjects appears to have been lower than that of shocked subjects, this difference was not significant $[F(1,33)=$ $3.33, p<.077]$.

Body weight. Body weight is shown in Figure 1C, expressed as the change from baseline intake. Exposure to shock decreased body weight dramatically $[F(1,33)=$ $42.98, p<.0001]$. More importantly, the yoked group did not differ from the shock group $[F(1,33)=3.52$, $p=.070]$.

\section{Discussion}

That shock induced both a decreased body weight and decreased food intake under ad-lib conditions is in accord with previous reports in the helplessness literature (Rickards et al., 1995; Wagner et al., 1977; Weiss, 1968, 1970). The food-yoking procedure successfully equated the intake of food-yoked and shock groups. The main find-

Table 1

Baseline Food and Water Intake and Body Weight by Group, Expressed as the Mean and Standard Error of the Mean (SEM) for Experiment 1

\begin{tabular}{|c|c|c|c|c|c|c|}
\hline \multirow[b]{2}{*}{ Group } & \multicolumn{2}{|c|}{ Body Weight } & \multicolumn{2}{|c|}{ Food } & \multicolumn{2}{|c|}{ Water } \\
\hline & $M$ & $S E M$ & $M$ & $S E M$ & $M$ & $S E M$ \\
\hline Control & 488.4 & 6.4 & 28.2 & 0.32 & 26.2 & 0.57 \\
\hline Shock & 488.4 & 6.1 & 27.8 & 0.37 & 27.5 & 1.0 \\
\hline Yoked & 488.6 & 6.3 & 27.4 & 0.38 & 25.8 & 0.60 \\
\hline
\end{tabular}

Note-Measurements are in grams. 

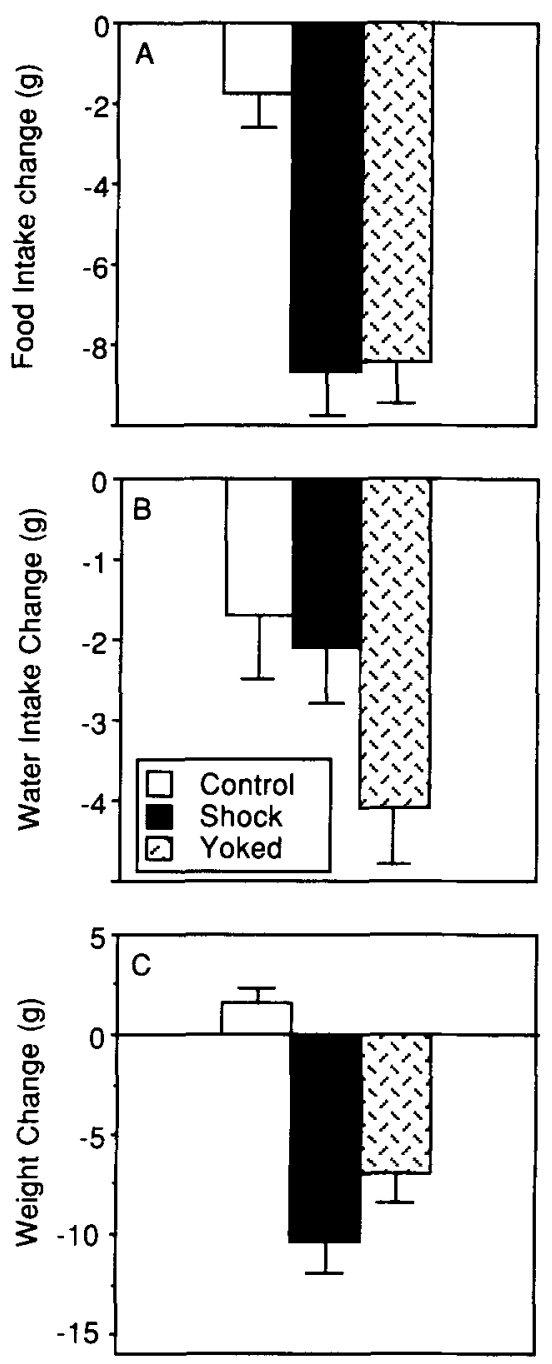

Figure 1. Experiment 1: Food intake (A), water intake (B), and body weight $(C)$ for the 24-h period commencing with stress, expressed as the mean change from baseline with standard errors. Shock animals received exposure to 110 footshocks; control and yoked animals were merely exposed to the apparatus. After the stress session, each yoked animal's food intake for the poststress period was determined by the free-food intake of its age- and weight-matched partner in the shock group.

ing of this experiment is that the stress-induced hypoingestion can cause the decreased weight observed, since shock and yoked groups differed neither for food and water intake, nor body weight change. It seems that shock exposure affected food intake, and that this in turn was a sufficient cause of the body weight decrease. Whether this was the case beyond the initial poststress period was the concern of Experiment 2.

\section{EXPERIMENT 2}

In this experiment, we observed four groups over 10 poststress days. We expected that shocked subjects would eat less and weigh less in the first poststress measure than controls. Thereafter, they should gain weight at the same rate as controls, supported by a recovery of food intake to the level of controls (Rickards \& Job, 1997; Rickards et al., 1995). Given the results of Experiment 1, we hypothesized that the food intake poststress would cause the weight pattern. To assess this, a third group, yokedlong (YL), food-yoked to the shock group for the entire duration of test days, was compared with the shock group and with a group food-yoked to the shock group for the first test day only, yoked-short (YS).

Rickards and colleagues found that while shocked groups recovered their food intake and rate of weight gain to control levels, no compensatory increase in food intake occurred (Rickards \& Job, 1997; Rickards et al., 1995). In contrast, rats and humans that have lost weight because of acute food restriction have been reported to compensate by hyperingestion, if returned to ad-lib diets (LeMagnen, 1983; Levitsky, 1970; Levitsky, Faust, \& Glassman, 1976, Experiment 1), in such a way that they achieve a body weight that probably would have existed had no restriction occurred. Given this, it seemed possible that stress not only induced a transient weight loss by reducing food intake, but might also have prevented a compensatory hyperingestion that might have recovered this loss. We examined this possibility in Experiment 2 by comparing the shock group with Group YS. Subjects in this group were treated in the same way as the yoked subjects for the first $24 \mathrm{~h}$ of the experiment; they were food-yoked to a partner in the shock group for the first poststress period only. After this food restriction, they were returned to ad-lib access to food and water. If a compensatory increase in food intake occurred in Group YS relative to Group $S$ and allowed recovery of body weight, this would be evidence that shock prevents a compensatory hyperingestion that allows recovery of the weight initially lost.

A further aim of the second experiment was to examine the possible contribution of defecation during stress to the lower weight of stressed subjects. Defecation during stress procedures is well documented and regarded as a reliable indication of "emotionality" or degree of subjective distress (Champion, 1969; Hall, 1934; Ragusa, Shemberg, \& Rasbury, 1968; Sudha \& Pradhan, 1993). Given the ability of food intake to account for weight decrease poststress (Experiment 1), it seems unlikely that weight lost during stress due to defecation, and so forth, can contribute to an explanation of stress-induced weight changes. However, examination of both stressinduced defecation and changes in food intake addressed this issue.

\section{Method}

Subjects. Forty-eight subjects were selected from an initial pool of 60 experimentally naive male Wistar rats. Selection was made on the basis of close matching for body weight and food intake. The subjects were between 92 and 95 days of age and weighed between 410 and $508 \mathrm{~g}$ at the start of the experiment. They were housed and treated in the same manner prior to manipulations as in the previous experiment. All experimental manipulations occurred during the light period. 
Apparatus. The shock apparatus and treatment were the same as in the previous experiment.

Procedure. The procedure was largely the same as for Experiment 1 . An initial match on weight and food intake yielded 12 tetrads. Control and shock animals from the first and second tetrads were treated on Day 6. Yoked-long and yoked-short animals from these tetrads were then treated on Day 7, to allow for the foodyoking procedure. Baseline measures were continued for all unallocated rats during this phase. Any adjustments to group allocations could therefore be made daily. This procedure was continued until all tetrads were run.

The control and yoked groups were exposed to the apparatus for a complete session but received no shocks. The fecal boli for each subject were removed from the tray and weighed at the end of the session. Fecal boli excreted in the home cage after the animals had been returned from the stress session were collected and weighed at 0830 the next morning. Poststress observation of food and water intake and body weight was continued for 10 test days in total.

Food-yoking poststress within each tetrad was such that the food intake of the shocked rat for the first measure poststress determined the food made available to the yoked-long and yoked-short rats for the same period. Thereafter, the yoked-short animal was returned to ad-lib access to food, while the yoked-long animal remained yoked to its shock partner's food intake for the duration of the experiment

Statistics. The Type I error rate of .05 was used for all analyses. All statistical tests reported were planned contrasts with one-way analysis of variance. Previous work suggested that the first $72 \mathrm{~h}$ poststress were critical (Rickards \& Job, 1997; Rickards et al., 1995). Contrasts on each of the first 3 test days, and on the last test day compared Groups C and S, Groups S and YL, and Groups S and YS. These contrasts were carried out for all measures except defecation. To assess group differences in defecation, the shock groups' defecation was compared with that of Groups C, YL, and YS for both the period of treatment and the total for the first test day.

\section{Results}

Baselines. The four groups did not differ on any prestress measure $(p s>.1)$. Baseline means and standard errors are reported in Table 2. A procedural error in food access on Test Day 4 affected food intake and body weight data from this point onward in 8 animals. Consequently, data analysis for all measures included all subjects $(N=$ 48 ) for the first 3 test days and $N=40$ for the last test day. Figures include the 40 subjects carried through the experiment.

Food intake. Food intake on the day beginning with the stress procedure, and on the 9 days following, is shown in Figure 2A as the change from baseline. Group $\mathrm{C}$ showed a steady intake over test days, although it seemed to be at or slightly below baseline. Group S showed an initial reduction in feeding from baseline of $13.41 \mathrm{~g}$ on the average. On the following test day (TD) this group's intake recovered substantially to only $2.4 \mathrm{~g}$ below baseline. By the last test day, TD10, this group's intake was less than $1 \mathrm{~g}$ below baseline. Planned contrasts confirmed that Group $\mathrm{S}$ ate less than Group $\mathrm{C}$ on the first poststress pe$\operatorname{riod}[F(1,44)=96.11, p<.0001]$, a nonsignificantly different amount at TD2 $[F(1,44)=3.00, p=.090]$, slightly less at TD3 $[F(1,44)=4.50, p=.040]$, and a nonsignificantly different amount at $\operatorname{TD} 10[F(1,36)=0.01$, $p=.926]$. Again the yoking procedure was effective. Groups YL and S did not differ on TD1, TD2, TD3, or
Table 2

Baseline Food and Water Intake and Body Weight by Group, Expressed as the Mean and Standard Error of the Mean (SEM) for Experiment 2

\begin{tabular}{|c|c|c|c|c|c|c|}
\hline \multirow[b]{2}{*}{ Group } & \multicolumn{2}{|c|}{ Body Weight } & \multicolumn{2}{|c|}{ Food } & \multicolumn{2}{|c|}{ Water } \\
\hline & $M$ & $S E M$ & $M$ & $S E M$ & $M$ & $S E M$ \\
\hline$\overline{\text { Control }}$ & 467.3 & 6.91 & 33.0 & 0.49 & 28.3 & $\overline{0.70}$ \\
\hline Shock & 466.2 & 6.21 & 33.0 & 0.57 & 27.7 & 0.65 \\
\hline Yoked-lon & 467.4 & 6.56 & 32.3 & 0.55 & 26.1 & 0.75 \\
\hline Yoked-short & 467.3 & 6.66 & 33.3 & 0.48 & 28.2 & 0.98 \\
\hline
\end{tabular}

Note-Measurements are in grams.

TD10 (all $p s>.1$ ), indicating that Group YL did not leave significant amounts of food uneaten.

Group YS showed a markedly different pattern of food intake to Group S. On TD1, the two groups did not differ $(p>.1)$. However, Group YS, having been returned to ad-lib access to food for TD2, had compensated for the prior restriction by increasing food intake by $4.14 \mathrm{~g}$ beyond Group S's recovered level $[F(1,44)=13.0, p=$ .0011 . Since Groups S and C were similar on TD2, Group YS may be inferred to have increased food intake to a level of feeding above that of controls. This elevation persisted on TD3 $[F(1,44)=27.17, p<.0001]$ and had dissipated by TD10 $[F(1,36)=1.63, p=.210]$, although inspection of Figure 2A suggests that this dissipation had occurred earlier at TD4. There were no group differences by TD10 (all $p$ s $>.1$ ).

Water intake. Water intake as a change from baseline is shown in Figure 2B for the first 4 test days. A minor procedural error on 1 test day meant that some data points were lost for days ranging from TD5 to TD7, from different tetrads. Nevertheless, all rats enjoyed their usual water access. While Group $S$ appeared to drink less relative to Group C on TD1, and thereafter to maintain a recovery to control levels established on TD2, drinking for the two groups was not significantly different on TD1, TD2, TD3, or TD10 $[F(1,44)=3.325, p=.075 ; F(1,44)$ $=1.026, p=.317 ; F(1,44)=1.183, p=.283 ; F(1,36)=$ $0.033, p=.858$, respectively].

As in Experiment 1, the food-yoking procedure appeared to produce a pattern of water intake for yoked groups similar to that of Group S. Group YL did not differ from Group $S$ on any of the days subjected to planned contrasts $[F(1,44)=2.25, p=.141 ; F(1,44)=3.55$, $p=.066 ; F(1,44)=2.22, p=.144 ;$ and $F(1,36)=$ $0.34, p=.562$ for TD1, TD2, TD3, and TD10, respectively]. Group YS did not differ from Group S on TD1 $(p>.1)$, but drank more than Group $\mathrm{S}$ on the 2nd test day $[F(1,44)=5.95, p=.019]$, accompanying the food increase on return to ad-lib access. While this group's drinking appeared to remain elevated on TD3 relative to that of Group $\mathrm{S}$, this did not reach statistical significance $[F(1,44)=4.02, p=.051]$, and by TD10 there were no group differences (all $p s>.07$ ).

Body weight. Body weights on the day beginning with the stress procedure, and on the 9 days following, are 

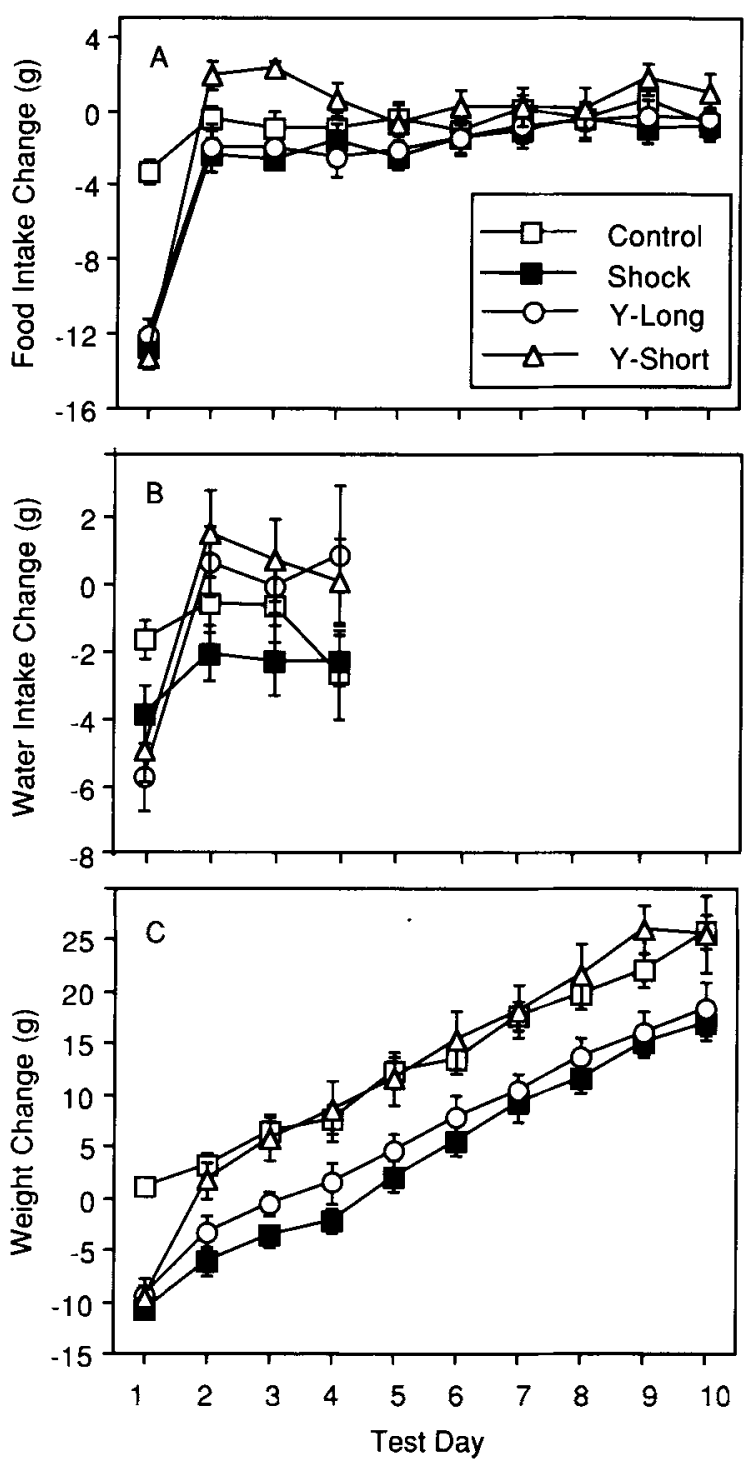

Figure 2. Experiment 2: Food intake (A), water intake (B), and body weight $(C)$ for the 10 test days poststress, expressed as the mean change from baseline with standard errors. Shock animals received exposure to 110 footshocks; control and yoked animals were merely exposed to the apparatus. After the stress session, each yoked-long animal's maximum daily food intake was determined by the free-food intake of its age and weight matched partner in the shock group. Group yoked-short was food yoked to group shock for 24-h only, and thereafter returned to ad-lib access. See text for details.

shown in Figure $2 \mathrm{C}$ as the change from baseline. After an initial loss on the 1st test day, Groups $S$ and $Y L$ recovered a rate of weight gain similar to that of controls. This rate of gain was supported by the substantially recovered level of feeding. However, the initial weight loss was not regained. In contrast, Group YS, after the same initial weight loss, recovered so that they were indistinguishable from controls. This recovery was supported by the compensatory hyperingestion reported above.
At TD1 the three groups with the lower food intake also appeared to have lower body weight relative to controls. Groups YL and YS were similar to Group S (all $p \mathrm{~s}>$ .1 ), with the three groups losing $10.92,9.75$, and $10.38 \mathrm{~g}$, respectively, from baseline. Group $\mathrm{S}$ had lost a significant amount of weight relative to Group $\mathrm{C}[F(1,44)=$ $69.34, p<.0001]$. At TD2, the two groups that had recovered feeding to control levels, Groups $\mathrm{YL}$ and $\mathrm{S}$, did not recover body weight to those levels. This pattern held for TD3 and TD10, although the two groups appeared to show a rate of weight gain similar to that for controls. Groups YL and S were similar $(p>.1)$, and the latter weighed less than controls on these days $[F(1,44)=31.07$, $p<.0001 ; F(1,44)=27.92, p<.0001 ; F(1,36)=5.75$, $p=.022$, respectively]. The compensatory increase in feeding by YS, however, supported a weight recovery so that they appeared indistinguishable from controls and weighed significantly more than the shock animals on these test days $[F(1,44)=20.18, p<.0001 ; F(1,44)=$ $17.91, p<.0001 ; F(1,36)=5.50, p=.025$, respectively].

Feces. Fecal weight for the lst test day (including the stress session) is shown in Figure 3. Not surprisingly, the shock group defecated more than Group $\mathrm{C}, \mathrm{YL}$, or YS during the treatment $[F(1,44)=14.92, p<.0001$; $F(1,44)=12.56, p=.001$; and $F(1,44)=12.82, p=$ .001 , respectively]. Collapsed across the two contexts, treatment and home cage, Group S's total defecation was less than that of the controls $[F(1,44)=4.81, p=.034]$, but similar to that of the two yoked groups $(p s>.1)$.

\section{Discussion}

The main finding of Experiment 1 was confirmed. On the 1 st test day, shock induced a decrease in eating-although not a reliable decrease in drinking which appears to have caused the weight loss. Subsequently, the rate of body weight gain appeared to recover to control levels when the feeding of the shock group recovered to control levels. However, the initial loss was not recov-

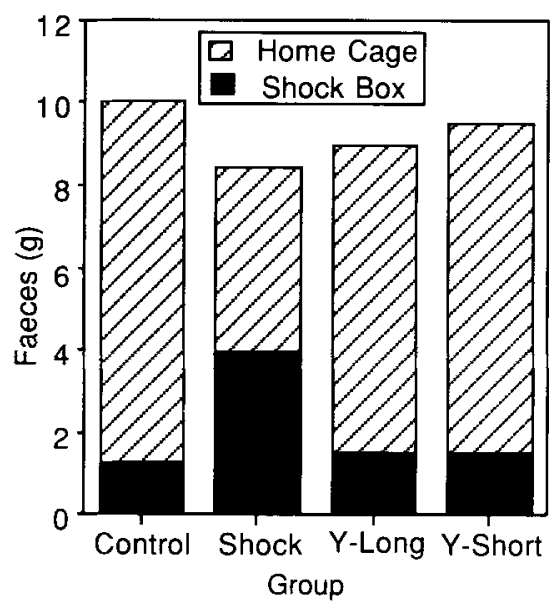

Figure 3. Experiment 2: Mean total defecation for the four groups separated into the two contexts, the treatment apparatus and home cage. 
ered in the test period, replicating Rickards et al. (1995). More importantly, Experiment 2 extended these findings. The similarity of Groups YL and S not only for ingestion, but also for body weight, demonstrated that the feeding pattern exhibited over the 10 test days poststress could be causal with respect to the body weight pattern observed over the same time period.

Comparison of Groups S and YS demonstrated a further effect of stress on ingestion. After similar hypoingestion and weight loss in the first test period, the two groups were both on ad-lib access to food and water. However, only Group YS immediately increased food and water intakes above the levels of controls, with the consequence that both initial body weight loss and rate of weight gain were recovered for this group. This compensation is in accord with the literature concerning acute food restriction (Le Magnen, 1983; Levitsky, 1970; Levitsky et al., 1976, Experiment 1). At no stage during the 10-day observation period did the shock group show such compensation, despite the free availability of food. It follows from this design that stress prevented the compensatory hyperingestion that would otherwise have occurred following such food restriction and body weight loss. What is most surprising, therefore, is not that body weight fails to recover to control levels. The cumulative food intake for the shocked group is less than that of controls, so they should weigh less. Rather, it is the failure of shocked subjects to show a compensatory increase in ingestion that is striking.

Although defecation has been reliably reported as contributing to weight lost during a stress session, whether that stress is shock, immobilization, or restraint (Chauoloff, Baudrie, \& Coupry, 1994; Siegel \& Siegel, 1949; Tanaka et al., 1989, Experiment 1; Williams, Peterson, Villar, \& Burks, 1987), the present experiment suggests that defecation in the treatment apparatus does not contribute to the lower body weight of shocked subjects observed at the conclusion of the initial $24-h$ period. Stress caused greater defecation in the treatment apparatus, but no greater defecation in total over the 1 st test day. The total for Group S was less than that for controls, but similar to that for the two yoked groups. The latter finding suggests that the decreased total defecation for shocked subjects was the result of decreased food intake. Shock seemed to change the distribution of defecation by producing a premature expulsion of feces during treatment. These results are in accordance with the claim that the proximal cause of weight change on the 1st test day poststress is food intake.

\section{GENERAL DISCUSSION}

The present experiments appear to resolve the issue of whether food intake and body weight poststress are related in the helplessness paradigm. The observation that an unshocked group showed the same body weight pattern as did the shock group to which it was food-yoked supports the hypothesis that stress has its effects on body weight via its effects on food intake. Stress caused Group S to eat significantly less than controls, hence the initial weight loss suffered by Group S. The recovery of Group S's food intake to the level of controls $24 \mathrm{~h}$ after shock caused the recovery of the rate of weight gain by that group to the level of controls. Indeed the food-yoking design allowed the demonstration that food intake was a sufficient cause of the body weight pattern.

In accordance with this is the finding that stress-induced defecation, and the weight loss to which it has been shown to contribute, do not seem to have a role in explaining the net weight change in the 24-h period commencing with stress. As noted above, stress caused greater defecation in the treatment apparatus, though no greater defecation in total. Rather, shock seemed to change the distribution of defecation by producing a premature expulsion of feces during treatment. Given that Groups S and YL showed the same body weight pattern despite the different distribution of defecation in the first test period, it seems that this factor did not contribute to the weight change.

Another method of testing the hypothesis that changes in food intake may be causal with respect to changes in body weight after stress is to compute correlations. Withingroup correlations of the change in body weight and change in food intake in the first poststress period for each group in the two experiments were uniformly positive, ranging from .92 to .04 (mean $=.45$ ). Three of the six correlations were significant $(p s<.05) .{ }^{1}$ However, these correlations are limited by the small sample size and consequent low power, the possible influence of other variables (such as baseline body weight) on weight loss, and the restricted range on at least one of the two variables, which decreases the observed correlation (Guilford, 1954). Nonetheless, the pattern of correlations is consistent with the casual sequence suggested by the more compelling between-group comparisons.

This causal sequence may hold for other types of stressors. That is, other stressors, when applied acutely, may also affect body weight as a result of effects on food intake. It seems that this possibility is greatest for cases in which intake and body weight measures are congruent. Consider immobilization stress, for example. There is evidence that body weight and intake changes are congruent in the first 24-h period commencing with the 2-h application of immobilization stress. A decrease in food intake has been reliably found to follow this stressor (Kennett, Chauoloff, Marcou, \& Curzon, 1986; Stone \& Platt, 1982) and to accompany a decreased body weight (Donohoe et al., 1987; Kennett et al., 1985a, 1985b). Interestingly, in 3 days poststress, neither compensatory feeding nor regain of the weight initially lost has been observed (Shimizu, Oomura, \& Kai, 1989). However, from Shimizu et al.'s Figure 2 it appears that recovery of food intake supported recovery of the rate of weight gain.

This causal sequence is unlikely to hold for chronic stress procedures. Chronic application of stressors may result in a dissociation of food intake and body weight (see Griffiths, Shanks, \& Anisman, 1992). Indeed, the dissociation of the two measures reported by Dess et al. (1989) may be seen as the result of chronic stress if the restricted 
feeding schedule on which the acute shock exposure is later imposed is itself a chronic stressor (Curzon, Joseph, \& Knott, 1972). However, the nature of this stressor is of special relevance to the body weight and ingestive measures, since it would directly alter the metabolic status of the subject prior to the acute shock exposure (LeMagnen, 1983; Rickards \& Job, 1997).

Generally, it is likely during chronic procedures that body weight changes are the result of a more complex causal sequence which includes changes in food intake, metabolic rate, efficiency of food utilization, and so forth. This sequence poststress is yet to be specified (Griffiths et al., 1992; Pare, 1965). Nonetheless, food intake changes are likely to have a significant role (Marti et al., 1993; Pare, Rothfield, Isom, \& Varady, 1973).

The present findings not only resolve empirical issues, but have theoretical ramifications. The present results suggest a revision of Dess's (1991) regulatory shift hypothesis (RSH). Dess (1991) advanced the RSH to account for stress-induced ingestive changes in terms of body energy regulation. Necessarily this also involves comment on body weight changes poststress. The hypothesis states that exposure to stress is a manipulation that shifts energy balance toward utilization of stored fat and promotes a conservative energy strategy. Evidence for the latter is taken to be the rejection of quinine adulterated food or fluid poststress ("finickiness"; see Dess, Chapman, \& Minor, 1988; Dess et al., 1989; Job \& Barnes, 1995 ) and increased intake of sucrose solution poststress (Dess, 1992; Dess and Choe, 1994). In the absence of diet adulteration, it is implied that stress would suppress intake of regular food chow (Dess, 1991, p. 247).

The sequence of the events identified by Dess, however, is unclear. Logically, such a stress-induced shift could occur in one of two ways, as a direct or indirect consequence of the stress. Stress, in the former case, is the proximal cause of the shift to utilization, with body weight and ingestive changes being secondary. The latter case refers to the more parsimonious sequence in which stress causes a decreased food intake, which in turn necessitates utilization of fat stores in the same manner as does food deprivation. The shift to utilization and the accompanying body weight decrease and conservative ingestive strategy may thus be secondary to the stress-induced hypoingestion. It has not been specified whether the direct or indirect causal sequence describes Dess's hypothesis.

The present results not only support the proposed indirect sequence of events poststress, but comment on the sufficiency of food intake as the cause of weight changes. With this revision, testable predictions may be derived from the RSH. The design of any test must employ ad-lib access to food and water, since any food or water deprivation schedule may in itself produce a shift to utilization of glycogen and fat stores. This would then obscure any such shift due to stress (Rickards et al., 1995). There is some evidence using indirect calorimetry that this shift to utilization of body fat does occur poststress (Rickards et al., 1996).
The present findings also have bearing on the longterm nature of stress-induced changes in ingestion and body weight and on their boundary conditions. Since the decreased food intake and body weight decrease are transient, it may be inferred that the shift to utilization of body fat is also transient. What does seem to persist, or at least what did persist for 10 days poststress in the present experiments, is the failure to compensate for the initial hypoingestion, and thus initial weight lost, in the manner that Group YS compensated. Just how "long term" this effect is remains to be investigated. For example, it may be that there is a critical period in which compensatory hyperingestion will occur, if at all, and that the adverse effects of stress extend only this far in time. Alternatively, given a longer period of observation, body weight may be seen to recover by other means such as increased food utilization and/or decreased metabolic rate (LeMagnen, 1983). If so, stress would have its effect on the mechanism of recovery, rather than on the fact of recovery.

These results have further implications for the helplessness model of depression, since they address the stressinduced body weight and ingestive changes that have been taken as further symptom parallels with human depression (Dess, 1991, 1992; Dess et al., 1989; Dess, Raizer, et al., 1988; Job \& Barnes, 1995; Seligman, 1975; Wagner et al., 1977; Weiss, 1968). The apparent endurance of the lower body weight in particular has been suggested to be greater than that of some other consequences of shock and has therefore been taken to have particular relevance to the criticism of the model that the effects of the stress session are transient, unlike the symptoms of depression that they are intended to model (Desan et al., 1988; Willner, 1984, 1986). Specifically, lowered body weight appears to be more enduring than active escape or avoidance learning deficits in rats, for example, which are usually reported to disappear $48-72 \mathrm{~h}$ poststress (Seligman et al., 1971). Exceptions to this time course have been noted, with shuttle-box performance deficits (Glazer \& Weiss, 1976a, 1976b; Seligman \& Groves, 1970) and Y-maze performance deficits (Maier, Coon, McDaniel, Jackson, \& Grau, 1979; Seligman, Roselinni, \& Kozak, 1975) reported at 7 days poststress. Similarly, several apparently dissipated effects reappear with mild reinstatement shocks (Anisman \& Sklar, 1979; Job \& Barnes, 1995; Weiss, 1968), suggesting a persistent vulnerability after stress to even mild stressors. Desan et al. (1988) argue, however, that since these "long-term" effects occur only after reexposure to the original stressor, or to cues associated with it, they may reflect rearousal of the effect rather than its persistence over time, and so may be of limited relevance to the helplessness model. However, reexposure to cues associated with the stressor may occur in the lives of depressed people. Furthermore, what these tests reveal is a persistent vulnerability, produced by the pretreatment, to even mild stressors.

A persistently lowered body weight due to a failure to increase ingestion to recover the initial weight lost may be another example of a longer term helplessness effect ap- 
parent in the absence of reinstatement, thus improving the face validity of this model of human depression (Overmier \& Helhammer, 1988; Seligman, 1975; Willner, 1986).

\section{REFERENCES}

Alario, P., Gamallo, A., Beato, M. J., \& Trancho, G. (1987). Body weight gain, food intake and adrenal development in chronic noise stressed rats. Physiology \& Behavior, 40, 29-32.

Armario, A., Castellanos, J. M., \& Balasch, J. (1984). Effect of crowding on emotional reactivity in male rats. Neuroendocrinology, 39, 330-333.

Anisman, H., \& SkLar, L. S. (1979). Catecholamine depletion upon reexposure to stress: Mediation of the escape deficits produced by inescapable shock. Journal of Comparative \& Physiological Psychology, 93, 610-625.

BALLEINE, B. E., \& JOB, R. F. S. (1991). Reconsideration of the role of competing responses in demonstrations of the interference effect (learned helplessness). Journal of Experimental Psychology: Animal Behavior Processes, 17, 270-280.

BARE, J. K., \& CiCALA, G. (1960). Deprivation and time of testing as determinants of food intake. Journal of Comparative \& Physiological Psychology, 53, 151-154.

Brennan, F. X., Job, R. F. S., Watkins, L., \& MaiER, S. F. (1992). Total plasma cholesterol levels of rats are increased following only three sessions of tailshock. Life Sciences, 50, 945-950.

Champion, R. A. (1969). Learning and activation. Sydney: Wiley.

Chauoloff, F., Baudrie, V., \& Coupry, I. (1994). Effects of chlorisondamine and restraint on cortical [3H]ketanserin binding, 5-HT2 A receptor-mediated head shakes, and behaviors in models of anxiety. Neuropharmacology, 33, 449-456.

Chavoloff, F., \& Zamfir, O. (1993). Psychoneuroendocrine outcomes of short-term crowding stress. Physiology \& Behavior, 54, 767-770.

Curzon, G., JosePh, M. H., \& KNotT, P. J. (1972). Effects of immobilization and food deprivation on rat brain tryptophan metabolism. Journal of Neurochemistry, 19, 1967-1974.

Desan, P. H., Silbert, L. H., \& MaIER, S. F. (1988). Long-term effects of inescapable stress on daily running activity and antagonism by desipramine. Pharmacology, Biochemistry \& Behavior, 30, 21-29.

Dess, N. K. (1991). Ingestion and emotional health. Human Nature, 3, 235-269.

DESs, N. K. (1992). Divergent responses to saccharin vs. sucrose availability after stress in rats. Physiology \& Behavior, 52, 115-125.

Dess, N. K., \& Chapman, C. D. (1990). Individual differences in taste, body weight, and depression in the "helplessness" rat model and in humans. Brain Research Bulletin, 24, 669-676.

Dess, N. K., Chapman, C. D., \& Minor, T. R. (1988). Inescapable shock increases finickiness about drinking quinine-adulterated water in rats. Learning \& Motivation, 19, 408-424.

DESS, N. K., \& CHOE, S. (1994). Stress selectively reduces sugar + saccharin mixture intake but increases proportion of calories consumed as sugar by rats. Psychobiology, 22, 77-84.

DESS, N. K., \& MinOR, T. R. (1996). Taste and emotionality in rats selectively bred for high versus low saccharin intake. Animal Learning \& Behavior, 24, 105-115.

Dess, N. K., Minor, T. R., \& BrewER, J. (1989). Suppression of feeding and body weight by inescapable shock: Modulation by quinine adulteration, stress reinstatement, and controllability Physiology \& Behavior, 45, 975-983.

Dess, N. K., Raizer, J., Chapman, C. D., \& GarCia, J. (1988). Stressors in the learned helplessness paradigm: Effects on body weight and conditioned taste aversion in rats. Physiology \& Behavior, 44, 483-490.

DEss, N. K., \& VANDERWEele, D. A. (1994). Lithium chloride and inescapable, unsignaled tail shock differentially affect meal patterns. Physiology \& Behavior, 56, 203-207.

Donohoe, T. P., Kennett, G. A., \& Curzon, G. (1987). Immobilisation stress-induced anorexia is not due to gastric ulceration. Life Sciences, 40, 467-472,

GI AZER, H. I., \& WEISS, J. M. (1976a), Long-term interference effect: An alternative to "learned helplessness." Journal of Experimental Psychology: Animal Behavior Processes, 2, 202-213.
GlaZER, H. I., \& WeIss, J. M. (1976b). Long-term and transitory interference effects. Journal of Experimental Psychology Animal Behavior Processes, 2, 191-201.

Griffiths, J., Shanks, N., \& Anisman, H. (1992). Strain-specific alterations in consumption of a palatable diet following repeated stressor exposure. Pharmacology, Biochemistry \& Behavior, 42, 219-227.

Gullford, I. P. (1954). Psychometric methods. Bombay: Tata McGraw Hill.

HALL, C. S. (1934). Emotional behavior in the rat: I. Defecation and urination as measures of individual differences in emotionality. Journal of Comparative \& Physiological Psychology, 18, 385-403

JoB, R. F. S., \& BaRNES, B. (1995). Stress and consumption: Inescapable shock, neophobia, and quinine finickiness in rats. Behavioral Neuroscience, 109, 106-116.

KeLSEY, J. E. (1977). Escape acquisition following inescapable shock in the rat. Animal Learning \& Behavior, 5, 83-92.

Kennet, G. A., Chauoloff, F., Marcou, M., \& Curzon, G. (1986). Female rats are more vulnerable than males in an animal model of depression: The possible role of serotonin Brain Research, 382, 416-421.

Kennett, G. A., Dickinson, S. L., \& Curzon, G. (1985a). Central serotonergic responses and behavioral adaptation to repeated immobilisation: The effect of the corticosterone synthesis inhibitor metyrapone. European Journal of Pharmacology, 119, 143-152.

Kennett, G. A., Dickinson, S. L., \& Curzon, G. (1985b). Enhancement of some 5-HT-dependent behavioral responses following repeated immobilisation in rats. Brain Research, 330, 253-263.

LARUE-ACHAGIOTIS, C., \& LeMAGNEN, J. (1983). Fast-induced changes in plasma glucose, insulin, and free fatty acid concentration compared in rats during night and day. Physiology \& Behavior, 30, 93-96.

LEMAGNEN, J. (1983). Body energy balance and food intake: A neuroendocrine regulatory mechanism. Physiological Reviews, 63, 314-386.

LEVITSKY, D. A. (1970). Feeding patterns of rats in response to fasts and changes in environmental conditions. Physiology \& Behavior, 5 , $291-300$

Levitsky, D. A., Faust, I., \& Glassman, M. (1976). The ingestion of food and the recovery of body weight following fasting in the naive rat. Physiology \& Behavior, 17, 575-680.

Maier, S. F., Coon, D. J., MCDaniel, M. A., Jackson, R. L., \& GRAU, J. (1979). The time course of learned helplessness, inactivity, and nociceptive deficits in rats. Learning \& Motivation, 10, 467-487.

Marti, O., Gavalda, A., Marti, J., Gil, M., Geralt, M., LopezCalderon, A., \& Armario, A. (1993). Chronic stress induced changes in LH secretion: The contribution of anorexia associated to stress. Life Sciences, 52, 1187-1194.

Minor, T. R., Dess, N. K., \& Overmier, J. B. (1991). Inverting the traditional view of "learned helplessness." In M. R. Denny (Ed.), Fear, avoidance, and phobias: $A$ fundamental analysis (pp. 87-133). Hillsdale, NJ: Erlbaum.

Ottenweller, J. E., Natelson, B. H., Pitman, D. L., \& Drastal., S. D. (1989). Adrenocortical and behavioral responses to repeated stressors: Toward an animal model of chronic stress and stress-related mental illness. Biological Psychiatry, 26, 829-841.

Overmier, J. B., \& Hell hammer, D. H. (1988). The learned helplessness model of human depression. Animal Models of Psychiatric Disorders, 2, 177-202.

PARE, W. P. (1965). Stress and consummatory behavior in the albino rat. Psychological Report, 16, 399-405.

Pare, W. P., Rothfield, B., Isom, K. E., \& Varady, A. (1973). Cholesterol synthesis and metabolism as a function of unpredictable shock stimulation. Physiology \& Behavior, 11, 107-110.

Prabhakar, T., \& Job, R. F. S. (1996). The effects of order of shock durations on learned helplessness in rats. Animal Learning \& Behavior, 24, 175-182.

Ragusa, D. M., Shemberg, K. M., \& Rasbury, W. (1968). Escapableinescapable shock and body weight loss. Psychonomic Science, 13, 45-46.

Rickards, S. L., Boakes, R. A., Prabhakar, T., Wood, A., Prior, G., ATrENS, D. M., \& JOB, R. F. S. (1996). Mediation of the metabolıc consequences of inescapable shock by hypoingestion: Implications for the regulatory shift hypothesis [Abstract]. International Journal of Psychology, 31, 462. 
Rickards, S. L., \& JoB, R. F. S. (1997). Food intake and body weight changes induced by stress depend upon feeding schedule. Manuscript in preparation.

RickardS, S. L., Job, R. F. S., \& BoAKES, R. A. (1995, December). The causal role of food intake in stress-induced changes in body weight and their time course. Paper presented to the Christmas Workshop of the Australian Learning Group.

Seligman, M. E. P. (1975). Helplessness: On depression, death, development, and death. San Francisco: Freeman.

Seligman, M. E. P., \& Groves, D. P. (1970). Nontransient learned helplessness. Psychonomic Science, 19, 191-192.

Seligman, M. E. P., Maier, S. F., \& Solomon R. L. (1971). Unpredictable and uncontrollable aversive events. In F. R. Brush (Ed.), Aversive conditioning and learning (pp. 347-400). New York: Academic Press.

Seligman, M. E. P., Roselinni, R. A., \& Kozak, M. (1975). Learned helplessness in the rat: Time course, immunization, and irreversibility. Journal of Comparative \& Physiological Psychology, 88, 542-547.

ShimizU, N., OOMURA, Y., \& KaI, Y. (1989). Stress-induced anorexia in rats mediated by serotonergic mechanisms in the hypothalamus. Physiology \& Behavior, 46, 835-841.

SiEgEL, P. S., \& SiEgel, H. S. (1949). The effect of emotionality on the water intake of the rat. Journal of Comparative \& Physiological Psychology, 42, 12-16.

Stone, E. A., \& Platt, J. E. (1982). Brain adrenergic receptors and resistance to stress. Brain Research, 237, 405-414.

Sudha, S., \& Pradhan, N. (1993). Behavioral consequences of predictable vs. unpredictable shocks in rats. Physiology \& Behavior, 54, 243-247.

Tanaka, M., Ida, Y., Tsuda, A., Tsujmara, S., Shirao, I., \&
OGuсні, M (1989). Met-enkaphalin, injected during the early phase of stress, attenuates stress-induced increases in noradrenaline release in rat brain regions. Pharmacology, Biochemistry \& Behavior, 32, $791-795$.

WAGNER, H. R., HALL, T. L., \& CoTE, I. L. (1977). The applicability of inescapable shock as a source of animal depression. Journal of General Psychology, 96, 313-318.

WEISs, J. M. (1968). Effects of coping responses on stress. Journal of Comparative \& Physiological Psychology, 65, 251-260.

WEISS, J. M. (1970). Somatic effects of predictable and unpredictable shock. Journal of Psychosomatic Medicine, 32, 397-408.

Williams, C., Peterson, J. M., Villar, R. G., \& Burks, T. (1987). Corticotropin-releasing factor directly mediates colonic responses to stress. American Journal of Physiology, 253, G582-G586.

WiL.LNER, P. (1984). The validity of animal models of depression. Psychopharmacology, 83, 1-16.

WILLNER, P. (1986). Validation criteria for animal models of human mental disorders: Learned helplessness as a paradigm case. Progress in Neuropsychopharmacology \& Biological Psychiatry, 10, 677-690.

\section{NOTE}

1. While there were seven groups in total from the two experiments, the data from Groups YS and YL of Experiment 2 were pooled in order to calculate the correlation for the first test period, since the two groups had been treated identically up to this point.

(Manuscript received October 7, 1996; revision accepted for publication February 25, 1997.) 